\title{
Early signs of atherosclerosis are associated with insulin resistance in non-obese adolescent and young adults with type 1 diabetes
}

\author{
Björn Rathsman ${ }^{1 *}$, Stefan Rosfors ${ }^{2}$, Åke Sjöholm³ and Thomas Nyström ${ }^{3}$
}

\begin{abstract}
Background: Patients with type 1 diabetes have a substantial risk of developing cardiovascular complications early in life. We aimed to explore the role of insulin sensitivity $\left(S_{i}\right)$ as an early factor of atherosclerosis in young type 1 diabetes vs. non-diabetic subjects.

Methods: Forty adolescent and young adult individuals (20 type 1 diabetics and 20 non-diabetics), age 14-20 years, without characteristics of the metabolic syndrome, participated in this cross-sectional study. After an overnight fast, $S_{i}$ was measured by hyperinsulinemic euglycemic clamp $\left(40 \mathrm{mU} / \mathrm{m}^{2}\right)$ and calculated by glucose infusion rate (GIR). Carotid intima-media thickness (CIMT) was measured in the common carotid artery with high-resolution ultrasonography. Risk factors of atherosclerosis (Body mass index [BMI], waist circumference, systolic blood pressure $[\mathrm{sBP}]$, triglycerides, low $\mathrm{HDL}$-cholesterol and $\mathrm{HbA}_{1 \mathrm{c}}$ ) were also investigated.

Results: CIMT was increased ( $0.52 \pm 0.1$ vs. $0.47 \pm 0.1 \mathrm{~mm}, P<0.01)$, whereas GIR was decreased $(5.0 \pm 2.1$ vs. $7.1 \pm 2.2$ $\mathrm{mg} / \mathrm{kg} / \mathrm{min}, P<0.01)$ in type 1 diabetics vs. non-diabetics. The differences in cIMT were negatively associated with $\mathrm{S}_{\mathrm{i}}$ $(r=-0.4, P<0.01)$ and positively associated with waist circumference $(r=0.34, P=0.03)$, with no such associations between BMI $(r=0.15, P=0.32)$, sBP $(r=0.09, P=0.58)$, triglycerides $(r=0.07, P=0.66), \mathrm{HDL}$-cholesterol $(r=0.10$, $P=0.55)$ and $\mathrm{HbA}_{1 c}(r=0.24, P=0.13)$. In a multivariate regression model, between cIMT (dependent) and group (explanatory), only adjustment for $S_{i}$ affected the significance $(B=0.08, P=0.11)$ vs. $(B=0.07, P<0.01)$ for the whole model. No interaction between cIMT, groups and $S_{i}$ was observed.
\end{abstract}

Conclusions: CIMT is increased and associated with insulin resistance in adolescent, non-obese type 1 diabetic subjects. Although, no conclusions toward a causal relationship can be drawn from current findings, insulin resistance emerges as an important factor reflecting early signs of atherosclerosis in this small cohort.

Keywords: Adolescent, Atherosclerosis, Carotid intima-media thickness, Insulin sensitivity, Type 1 diabetes

\section{Background}

Recent advances in diabetes treatment have been successful in postponing the development of microvascular complications through better glycemic control following intensive insulin treatment [1]. In contrast, macrovascular complications have been less affected by this intervention and seem to appear even before onset of hyperglycemia, particularly in patients with type 2 diabetes. In fact, the relative risk for cardiovascular disease

\footnotetext{
* Correspondence: bjorn.rathsman@sodersjukhuset.se

'Karolinska Institutet, Department of Clinical Science and Education, Sachs'

Childrens' Hospital, Södersjukhuset AB, Stockholm SE-118 83, Sweden

Full list of author information is available at the end of the article
}

(CVD) is even higher in type 1 diabetes, in which juvenile-onset diabetes and its renal complications are modifiers of the natural history of atherosclerosis [2]. Atherosclerosis usually starts with fatty streaks, and can already be seen in childhood [3,4]. Also, early signs of atherosclerosis can be detected by using noninvasive high resolution ultrasonography, measuring the intimamedia thickness of the common carotid artery (cIMT), which in turn positively correlates to and predicts CVD [5].

Increased risk for diabetes-related vascular complications is associated with components of the metabolic syndrome, in which insulin resistance might be an 
important factor [6,7]. However, in the Diabetes Control and Complications Trial type 1 diabetes patients with the highest insulin resistance assessed by estimated glucose disposal rate at baseline had the highest risk of developing both micro-, and macrovascular complications regardless of which treatment group they were randomized to [8]. Moreover, gender differences might occur early in the diabetic state, whereas girls being more insulin resistant, reflected by a higher $\mathrm{HbA}_{1 \mathrm{c}}$ and cholesterol levels, despite increased insulin dose after one year. This gender difference seems to prevail and even increase at time of puberty [9]. The impact of insulin resistance per se on CVD is not easy to determine since it is clustering with several other traditional risk factors, i.e. hypertension, obesity, elevated triglycerides and low levels of HDL-cholesterol [10]. Nevertheless, it has been evaluated in a mathematical model that preventing insulin resistance would yield as much as $40 \%$ of myocardial infarction prevention in young adults, regardless of the other risk factors involved in the metabolic syndrome [10].

To this end, increased cIMT has been demonstrated in adolescents with type 1 diabetes, i.e. in association with a blunted endothelial regenerative capacity and low adiponectin levels [11]. A number of studies show increased cIMT in children with the metabolic syndrome and insulin resistance [5,12-16], as well as in adolescent type 2 diabetes [17]. Notwithstanding this, studies on the relationship between insulin resistance and cIMT in young subjects with type 1 diabetes are scarce. Therefore, we sought to investigate early signs of atherosclerosis, measured as cIMT and its relation to insulin sensitivity $\left(\mathrm{S}_{\mathrm{i}}\right)$ using hyperinsulinemic euglycemic clamp technique, in a group of adolescent and young adult with type 1 diabetes compared with non-diabetic individuals, all without the metabolic syndrome.

\section{Methods \\ Subjects}

Twenty adolescent and young adult type 1 diabetes individuals from the diabetes outpatient clinic at Sachs' Children's Hospital, Stockholm, Sweden, were invited to participate in the study. Twenty healthy individuals constituted a control group. The latter were invited from schools from the same area as the diabetic children. Inclusion criteria were: known type 1 diabetes (diabetes group), diabetes duration $>1$ year (diabetes group), age $14-20$ years, willingness to participate in the study, and written informed consent. Exclusion criteria were: any use of oral anti-diabetic agents, lipid lowering medication, ACE/A-II inhibitor treatment and known metabolic syndrome, according to National Cholesterol Education Program Adult Treatment Panel III [18], when three or more criteria were present: 1) Waist circumference $>102 \mathrm{~cm}$ in men or $>88 \mathrm{~cm}$ in women; 2) Triglycerides $\geq 1.7 \mathrm{mmol} / \mathrm{l} ; 3)$ HDL-cholesterol $<1.0$ $\mathrm{mmol} / \mathrm{l}$, in men, or $<1.3 \mathrm{mmol} / \mathrm{l}$, in women; 4) systolic blood pressure $(\mathrm{sBP})>130 \mathrm{mmHg}$ or diastolic blood pressure $(\mathrm{dBP})>85 \mathrm{mmHg}$ or any use of antihypertensive medication; 5) Fasting plasma glucose $\geq 6.1 \mathrm{mmol} / \mathrm{l}$ (control group). As some discrepancies between how to define the metabolic syndrome occur we also used the definition of the metabolic syndrome set up by WHO [19]. For the participating adolescents under the age of 16 years $(n=7)$ we used the International Diabetes Federation (IDF) definition of metabolic syndrome in children and adolescents for the age group 10-16 years; Central obesity measured as waist circumference $\geq 90^{\text {th }}$ percentile (or adult cutoff if lower) plus any two of the risk factors; triglycerides $\geq 1.7 \mathrm{mmol} / \mathrm{l}$, HDL-cholesterol $<1.03 \mathrm{mmol} / \mathrm{l}$, sBP $\geq 130$ or $\mathrm{dBP} \geq 85 \mathrm{mmHg}$, fasting plasma glucose $\geq 5.6 \mathrm{mmol} / \mathrm{l}$ [20]. All participants were evaluated for Tanner stage of puberty at the time of the investigation. The evaluation was based on breast development and information on time of menarche for the girls [21] and testis volume and pubic hair development for the boys [22]. Informed consent was obtained from all participants, when applicable also from both parents. Ethical approval was obtained from the Swedish local ethics committee. The study was conducted according to the principles of the Declaration of Helsinki 1975.

\section{Study design}

This was a single centre, cross-sectional study. The primary endpoint was defined as mean group difference in cIMT and its relation to $S_{i}$, measured by glucose infusion rate (GIR), using hyperinsulinemic euglycemic clamp technique. Secondary endpoints were to explore factors in the metabolic syndrome i.e. Body mass index [BMI], waist circumference, sBP, triglycerides, HDL-cholesterol and $\mathrm{HbA}_{1 \mathrm{c}}$ and its relation to cIMT, and cross-sectional intima-media area (CIMA). Subjects were admitted to the metabolic research ward after a 12 hour overnight fast. Participants who were treated with continuous subcutaneous insulin infusion (CSII) were instructed to continue their basal infusion until the test began, and those who were treated with multiple daily injections (MDI) were instructed to take their long acting insulin the day before the test but no fast acting insulin in the morning of the test. Fasting blood tests were drawn for biochemical analysis, urine test for microalbuminuria and a euglycemic hyperinsulinemic clamp was performed. Subsequent measurement of the common carotid artery (cIMT and CIMA) was done using high-resolution ultrasonography. Retinopathy data are collected from routine care screening tests with fundus photographs taken every second year after 10 years of age. 


\section{Euglycemic hyperinsulinemic clamp}

The hyperinsulinemic clamp was performed as described by De Fronzo et al. [23]. In brief, one intravenous needle was placed in the antecubital vein on the left arm and a second one, in a retrograde fashion, on the back of the right hand. The right hand was kept warm with an electric device (Heated air box set at $55^{\circ} \mathrm{C}$, University of Nottingham, U.K) for intermittent sampling of arterialized venous blood. In the left arm needle, human Actrapid insulin (40 mU/m²; NovoNordisk A/S, Copenhagen, Denmark) was infused along with 20\% dextrose (Fresenius Kabi, Stockholm, Sweden). Based on arterialized blood glucose samples taken from the right hand vein catheter every 5 minutes, the rate of dextrose infusion was adjusted to achieve a blood glucose level of $5.0 \mathrm{mmol} / \mathrm{l}$, during the clamp. Whole-body $S_{i}$ was measured as GIR and calculated from the amount of dextrose infused during the last $30 \mathrm{~min}$ of the clamp divided by body weight $(\mathrm{kg})$ and period $(\mathrm{min})$ and expressed as $\mathrm{mg} / \mathrm{kg} / \mathrm{min}$. The glucose clamp-derived index of $\mathrm{S}_{\mathrm{i}}\left[\mathrm{S}_{\mathrm{i}}\right.$ index; in $\left.\left(10^{-4} \mathrm{dl} / \mathrm{kg} / \mathrm{min}\right) /(\mu \mathrm{U} / \mathrm{ml})\right]$ was calculated from $\mathrm{GIR}$, corrected for body weight, during the final $30 \mathrm{~min}$ as follows: $S_{i}$ index $=G R_{s s} / G_{s s} \times \Delta I_{s s}$, where $G R_{s s}$ is the steady state GIR $(\mathrm{mg} / \mathrm{min}), \mathrm{G}_{\mathrm{ss}}$ is the steady state blood glucose concentration $(\mathrm{mg} / \mathrm{dl})$, and $\mathrm{I}_{\mathrm{ss}}$ is the difference between basal and steady state plasma insulin concentrations $(\mu \mathrm{U} / \mathrm{ml})$. This calculation is assumed to correct for differences in prevailing glucose and insulin concentrations.

\section{Blood chemistry}

Fasting blood samples were drawn for analyses of $\mathrm{HbA}_{1 \mathrm{c}}$, insulin, C-peptide, total cholesterol, LDL-cholesterol, HDL-cholesterol, triglycerides and hsCRP, using the local clinical chemistry laboratory (Södersjukhuset, Stockholm). Urine analyses measuring albumin and creatinine secretion were done on one urine portion before the clamp and analyzed at the same laboratory. Blood glucose levels were determined by the glucose oxidase method with a glucose analyzer (2300 STAT PLUS; Yellow Springs Instruments, Yellow Springs, OH, USA). Serum insulin and C-peptide levels were analyzed by an immunometric method with monoclonal antibodies (Modular E 170, Roche Diagnostics Scandinavia, Stockholm, Sweden).

\section{Carotid intima-media thickness (cIMT)}

Left and right carotids were examined by one operator using a Siemens Acuson Sequoia ${ }^{\mathrm{TM}} 512$ Ultrasound System (Mountain View, CA, USA) with an $8 \mathrm{MHz}$ linear array transducer. The subject/s head was tilted in order to get the common carotid artery (CCA) just proximal to the bulb placed horizontally across the screen. Magnified pictures were frozen incidentally with the $\mathrm{R}$ wave on the electrocardiogram. The cIMT was defined as the distance between the leading edge of the lumen-intima echo and the leading edge of the media-adventitia echo in the far wall. Lumen diameter was defined as the distance between the leading edge of the intima-lumen echo of the near wall and the leading edge of the lumenintima echo of the far wall [24]. The distal part of the CCA, 5-10 mm proximal to the carotid bulb, was used for measurements of cIMT and lumen diameter. All measurements were performed by one operator, blinded to all other data, using an automated computerized analyzing system [25]. The computer system calculated the average intima-media thickness and lumen diameter of the analyzed section. CIMA was calculated using the formula [(lumen diameter $+2 \times$ IMT) $/ 2]^{2} \times 3.14$ - (lumen diameter $/ 2)^{2} \times 3.14$ [26]. cIMT and CIMA were calculated from left and right CCA measurements $[(\sin +d x) / 2]$. As cIMT of multiple measurements is most widely used [27], it was chosen as our primary end point measurement.

\section{Statistics}

Results are shown as means \pm SD. Comparisons between study groups were made by using Student's $t$ test for independency. Test of normality was conducted with Kolmogorov-Smirnov and Shapiro Wilks test. For those parameters not normally distributed, Mann Whitney test was used for comparison between groups. McNemar's and sign tests were used for dichotomous variables. Spearman test was used for the correlation data. A stepwise multivariate regression analyses were used for further testing associations between cIMT (dependent) and group (explanatory) regarding atherosclerotic risk factors, i.e. $\mathrm{S}$, $\mathrm{BMI}$, waist circumference, $\mathrm{sBP}$, triglycerides, HDL-cholesterol and $\mathrm{HbA}_{1 \mathrm{c}}$. All riskfactors were included and successively excluded in order starting with $\mathrm{S}_{\text {i. }} \mathrm{P}<0.05$ was considered statistically significant. All statistical analyses were performed using PASW/SPPSS Statistics 18 software package.

\section{Results}

\section{Group characteristics and metabolic parameters}

All clinical and biochemical of the study groups are shown in Table 1 . All 40 participants were of Caucasian ethnicity. The type 1 diabetic group had mean diabetes duration of 7.3 years. Mean $\mathrm{HbA}_{1 \mathrm{c}}$ in the diabetes group was $74 \mathrm{mmol} / \mathrm{mol}$ (DCCT standard $=8.9 \%$ ). Seven of the type 1 individuals were treated with CSII and 13 with MDI. Those treated with CSII had a mean insulin dose of $0.84 \mathrm{U} / \mathrm{kg} /$ day and the ones on MDI $0.94 \mathrm{U} / \mathrm{kg} /$ day. There was no difference in $\mathrm{HbA}_{1 \mathrm{c}}$ between CSII and MDI treated diabetics $(68 v s .77 \mathrm{mmol} / \mathrm{mol}, P=0.34)$. As expected, glucose homeostasis differed between groups; however there were no significant differences in BMI, waist, blood pressure or in lipid profile between type 1 
Table 1 Clinical, biochemical, metabolic and vascular characteristics of the study groups

\begin{tabular}{|c|c|c|c|}
\hline Variables & Type 1 diabetes & Controls & $P$ \\
\hline Age (yrs) & $18 \pm 1.5$ & $18 \pm 1.7$ & 0.75 \\
\hline Sex (female/male) & $8 / 12$ & $13 / 7$ & 0.11 \\
\hline Pubertal stage nr (\%) & & & 0.28 \\
\hline 2 & 1 & 0 & \\
\hline 4 & 2 & 2 & \\
\hline 5 & 17 & 18 & \\
\hline Smoking (n) & 1 & 4 & 0.38 \\
\hline Body weight (kg) & $71.4 \pm 15.7$ & $68.1 \pm 11.3$ & 0.54 \\
\hline Height (cm) & $174 \pm 11$ & $173 \pm 8$ & 0.84 \\
\hline BMI $\left(\mathrm{kg} / \mathrm{m}^{2}\right)$ & $23.5 \pm 3.8$ & $22.8 \pm 4.0$ & 0.44 \\
\hline Waist circumference (cm) & $81.7 \pm 14$ & $76.2 \pm 9$ & 0.17 \\
\hline sBP (mmHg) & $116 \pm 12$ & $116 \pm 13$ & 0.95 \\
\hline $\mathrm{dBP}(\mathrm{mmHg})$ & $72 \pm 9$ & $73 \pm 8$ & 0.83 \\
\hline Diabetes duration yrs (range) & $7.3 \pm 4(1-14)$ & - & \\
\hline Insulin dose U/kg/day & $0.9 \pm 0.2$ & - & \\
\hline \multicolumn{4}{|l|}{ Retinopathy } \\
\hline None & 12 & - & \\
\hline Mild & 7 & - & \\
\hline Moderate & 1 & - & \\
\hline Microalbuminuria (yes/no) & $2 / 18$ & $0 / 20$ & \\
\hline Fasting plasma glucose (mmol/l) & $8.6 \pm 3.6$ & $4.6 \pm 0.3$ & \\
\hline $\mathrm{HbA}_{1 \mathrm{c}}(\mathrm{mmol} / \mathrm{mol})$ & $74 \pm 18.6$ & $35 \pm 1.9$ & \\
\hline Fasting C-peptide (nmol/l) & $0.1 \pm 0.4$ & $0.5 \pm 0.2$ & \\
\hline Total cholesterol (mmol/l) & $3.9 \pm 0.8$ & $3.6 \pm 0.8$ & 0.18 \\
\hline Triglycerides (mmol/l) & $0.8 \pm 0.3$ & $0.8 \pm 0.3$ & 0.87 \\
\hline HDL cholesterol (mmol/l) & $1.3 \pm 0.3$ & $1.4 \pm 0.3$ & 0.36 \\
\hline LDL cholesterol (mmol/l) & $2.2 \pm 0.9$ & $1.9 \pm 0.5$ & 0.13 \\
\hline hsCRP (mg/l) & $2.1 \pm 2.9$ & $1.8 \pm 2.8$ & 0.75 \\
\hline GIR (mg/kg/min) & $5.0 \pm 2.1$ & $7.1 \pm 2.2$ & $<0.01$ \\
\hline $\mathrm{S}_{\mathrm{i}}$ index $\left[\left(10^{-4} \mathrm{dl} / \mathrm{kg} / \mathrm{min}\right) /(\mu \mathrm{U} / \mathrm{ml})\right]$ & $10.2 \pm 6.7$ & $14.8 \pm 5.7$ & $<0.05$ \\
\hline cIMT (mm) & $0.52 \pm 0.1$ & $0.47 \pm 0.1$ & $<0.01$ \\
\hline $\mathrm{CIMA}\left(\mathrm{mm}^{2}\right)$ & $9.92 \pm 0.8$ & $8.94 \pm 1.3$ & $<0.01$ \\
\hline Lumen diameter (mm) & $5.58 \pm 0.3$ & $5.56 \pm 0.4$ & 0.85 \\
\hline
\end{tabular}

CIMT, intima-media thickness of the common carotid artery; CIMA, crosssectional intima-media area; GIR, glucose infusion rate; $S_{i}$ index (see text for definition); $s B P$, systolic blood pressure; $d B P$, diastolic blood pressure; Pubertal stage is defined as Tanner stage B1-5 for girls and G1-5 for boys, as well as gonadal development.

diabetic and healthy groups (Table 1). Mild retinopathy was found in seven diabetics and moderate in one. Statistical analysis showed significant correlation between diabetes duration and retinopathy $(\beta=0.65, P<0.001)$.

\section{Clamp data}

The type 1 diabetes group was insulin resistant, demonstrating a significantly lower GIR compared to the non- diabetic group (Table 1). The glucose clamp-derived index of insulin sensitivity $\left(S_{\mathrm{i}}\right.$ index; adjusting for insulin concentration during clamp) was correspondingly lower in the diabetes group compared to the non-diabetic group (Table 1).

\section{Carotid measurements}

The type 1 diabetes individuals had a significantly increased cIMT and CIMA (Table 1). There was no difference in carotid lumen diameter between groups (Table 1).

\section{Correlation data and regression analysis}

$\mathrm{S}_{\mathrm{i}}$ was negatively associated with cIMT, whereas waist circumference was positively associated with cIMT (Table 2). No such associations were observed for the other atherosclerotic risk factor (Table 2). The correlation, between $S_{i}$ and cIMT, for each group are given in Figure 1. When introducing all the above atherosclerotic risk factors (i.e. waist circumference, $\mathrm{BMI}, \mathrm{sBP}$, triglycerides, low HDL-cholesterol levels and $\mathrm{HbA}_{1 \mathrm{c}}$ ), in a multivariate regression model, whereas cIMT and group were the dependent and explanatory factors, respectively, $S_{i}$ abolished the significant association between cIMT and group, with no such effects for the other factors (Table 3). Whenever the $S_{i}$ factor was excluded but including one or more of the other risk factors in multivariate analyses the association between cIMT and group were, again, significant (data not shown). Adjustment for insulin concentration $\left(S_{\mathrm{i}}\right.$ index), in the model, did not change the results $(r=0.021, P=0.07)$, suggesting that insulin infusion in the clamp not was a confounder. No interaction between groups for the association between $S_{i}$ and cIMT was observed.

\section{Discussion}

We show that non-obese young adults with type 1 diabetes have early signs of atherosclerosis, as reflected by a significantly increased cIMT concomitant with lower insulin sensitivity, compared with matched non-diabetic

Table 2 Correlation between CIMT (dependent) and metabolic factors for atherosclerosis in all subjects $(n=40)$

\begin{tabular}{lll}
\hline Variables & $\boldsymbol{r}$ & $\boldsymbol{P}$ \\
\hline $\mathrm{S}_{\mathrm{i}}$ & -0.40 & $<0.01$ \\
Waist circumference & 0.34 & 0.11 \\
$\mathrm{BMI}$ & 0.15 & 0.03 \\
$\mathrm{SBP}$ & 0.09 & 0.58 \\
Triglycerides & 0.07 & 0.66 \\
$\mathrm{HDL}$-cholesterol & 0.10 & 0.55 \\
$\mathrm{HbA}_{1 \mathrm{C}}$ & 0.24 & 0.13 \\
\hline
\end{tabular}

$B M I$, Body mass index; $S_{i}$ Insulin sensitivity; $s B P$, systolic blood pressure. 


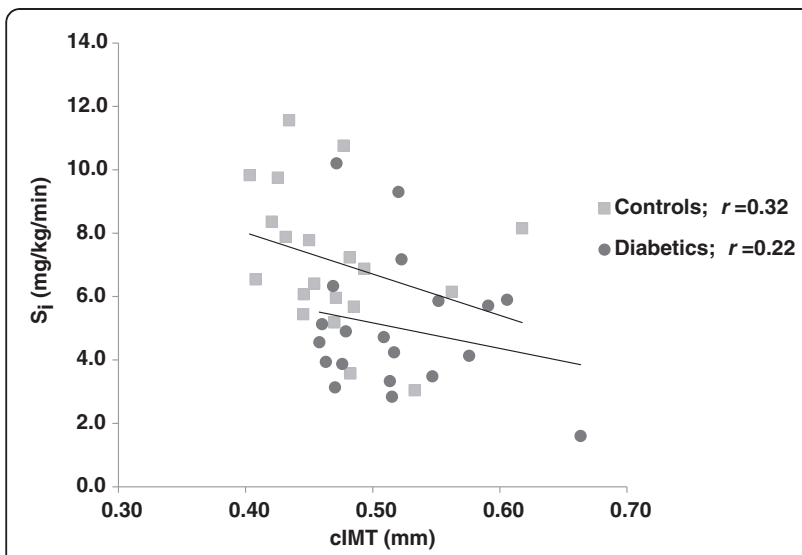

Figure 1 Correlation between cIMT (dependent) and $\mathrm{S}_{\mathrm{i}}$ in diabetics and controls, respectively.

individuals. In addition, insulin sensitivity correlated inversely with cIMT, regardless of glycemic control, blood pressure, lipids and BMI.

Young adults with an increased burden of components of the metabolic syndrome have increased cIMT, in whom hypertension and low HDL-cholesterol levels seem to be powerful predictors [16]. Importantly the young type 1 diabetes individuals in the present study were insulin resistant despite any clinical characteristics of the metabolic syndrome and, therefore, enabled us to investigate the correlation between insulin sensitivity per se and cIMT. Recently, in attempt to examine the influence of insulin sensitivity on cIMT, young adults were investigated with the clamp technique but no relationship was observed between these factors [13]. This is in contrast to other studies [28-32], as well as the present study. We have no good explanation for this observation, although differences in population, variations in cardiometabolic risk profile and extent of insulin

Table 3 Stepwise regression analysis of explanatory factors between cIMT (dependent) and group (controls and type 1 diabetes)

\begin{tabular}{|c|c|c|}
\hline Explanatory & $\beta$ & $P$ \\
\hline \multicolumn{3}{|l|}{ Included } \\
\hline All factors ${ }^{*}$ & 0.07 & $<0.01$ \\
\hline \multicolumn{3}{|c|}{ Excluded (stepwise in order) } \\
\hline$S_{i}$ & 0.08 & 0.11 \\
\hline Waist circumference & 0.09 & 0.03 \\
\hline BMl & 0.10 & $<0.01$ \\
\hline sBP & 0.09 & 0.01 \\
\hline Triglycerides & 0.08 & $<0.01$ \\
\hline HDL-cholesterol & 0.08 & $<0.01$ \\
\hline $\mathrm{HbA}_{1 \mathrm{c}}$ & 0.05 & $<0.01$ \\
\hline
\end{tabular}

${ }^{*} \mathrm{~S}_{\mathrm{i}}$, BMI, Waist circumference, sBP, Triglycerides, $\mathrm{HDL}$-cholesterol and $\mathrm{HbA} \mathrm{Ac}_{1 \mathrm{c}}$. resistance make these studies not easily comparable [33]. At the same time development of factors in the metabolic syndrome seems to be fairly similar in different populations of children and adolescents [34]. Notwithstanding this, our finding is consistent with some previous studies suggesting that insulin resistance is a major component of the metabolic syndrome, beyond glycemic control and clinical characteristics for the metabolic syndrome, in young type 1 diabetes [35-37].

Despite no differences in blood pressure, waist circumference, BMI, plasma lipid levels or smoking habits, cIMT was significantly increased in type 1 diabetic subjects compared to healthy individuals. Clustering of metabolic factors, such as hyperglycemia and insulin resistance, are risk factors suggested to be involved in the progression of cIMT [16,38]. Interestingly, after adjustment of the components in the metabolic syndrome i.e. blood pressure, BMI, waist circumference, triglycerides, $\mathrm{HDL}$ cholesterol and $\mathrm{HbA}_{1 \mathrm{c}}$, only $\mathrm{S}_{\mathrm{i}}$, affected group differences. This finding suggests that insulin resistance is the most powerful factor associated to cIMT in the current study. The correlation coefficient, and in particular the $r^{2}$ value, suggests that $16 \%$ of changes in cIMT can be accounted for by changes in $\mathrm{S}_{\mathrm{i}}$. In contrast, this correlation was smaller for each group tested suggested being due to the small sample size. There was also no interaction between groups, CIMT and $S_{\mathrm{i}}$, supporting the idea that insulin resistance is a single important factor for CVD in a general population $[10,39,40]$.

$\mathrm{HbA}_{1 \mathrm{c}}$ did not correlate with cIMT in the present study. Previous studies suggest that increased cIMT in type 1 diabetes patients is due to diabetes itself, concomitant with an increase in LDL cholesterol [41]. In contrast, long-term follow up studies clearly demonstrate that the progression of cIMT is largely explained by differences in $\mathrm{HbA}_{1 \mathrm{c}}$ [42], and that diabetes duration, sBP and BMI could influence the increment in CIMT in childhood and adolescent diabetes [43]. However, neither intensive diabetes treatment, nor levels of $\mathrm{HbA}_{1 \mathrm{c}}$, had any influences on early cIMT changes [44]. This might be explained by the involvement of formation of long-lived advanced glycation end products, highly reactive to the vessel wall, which usually takes several years to develop. Nevertheless, early and intensive insulin treatment in individuals with type 1 diabetes seems to be important to slow cIMT progression independent of other traditional CVD risk factors [42]. This is in contrast with a recent study demonstrating that a high $\mathrm{cu}-$ mulative dose of insulin associates with an increase in cIMT in type 1 diabetes. In an attempt to minimize the effect of insulin resistance as a potential confounder, these researchers investigated type 1 diabetes individuals [45]. We now clearly show that in our currently studied 
adolescent and young adult type 1 diabetes individuals, who, despite being devoid of any characteristics of the metabolic syndrome, are insulin resistant. The dysregulation of carbohydrate and lipid metabolism ensuing insulin resistance may serve to exacerbate the atherosclerotic progression. In the insulin resistant state, the normal suppression by insulin of free fatty acid release from adipose tissue is impaired so that the characteristic diabetic dyslipidemia occurs, i.e. hypertriglyceridemia, low HDL-cholesterol concentrations and elevation of free fatty acids. Defective insulin mediated fatty acid suppression also is suggested to induce insulin resistance in type 1 diabetes individuals [36]. Although our participants had no features of the metabolic syndrome, we cannot entirely exclude that high levels of free fatty acids might explain the association between insulin resistance and cIMT observed. Pro-coagulability and low grade inflammation, often seen in chronic hyperglycemia, can induce insulin resistance [46]. However, as there was no sign of low-grade inflammation in the present study, it is unlikely that heightened inflammatory activity was involved in the cIMT thickening in the diabetic subjects.

\section{Limitations}

The special strengths of the present study are worth emphasizing: only individuals without any clinical features of the metabolic syndrome took part in the study, which therefore allows us to investigate the role of insulin sensitivity per se on cIMT. However, certain weaknesses have to be mentioned as well: since this was a crosssectional study, we cannot draw any conclusions as to causal relationships between insulin resistance and cIMT. We also cannot exclude parameters other than the classical metabolic factors causing linkage between our findings such as non-esterified fatty acids.

\section{Conclusions}

We show that thickening of carotid intima-media, an established surrogate marker of early atherosclerosis, is inversely associated with insulin sensitivity in non-obese adolescent type 1 diabetes. Insulin resistance thus emerges as an important factor reflecting early signs of atherosclerosis in this small cohort. Further studies are warranted to mechanistically explore this finding in detail.

\section{Abbreviations}

sBP: Systolic blood pressure; dBP: Diastolic blood pressure; BMI: Body mass index; CCA: Common carotid artery; CIMT: Intima-media thickness of the common carotid artery; CIMA: Cross-sectional intima-media area; CVD: Cardiovascular disease; GIR: Glucose infusion rate; $S_{j}$ : Insulin sensitivity; CSII: Continuous subcutaneous insulin infusion; MDI: Multiple daily injections.
}

\section{Competing interests}

The authors declare that they have no competing interests.

\section{Authors' contributions}

All authors designed the study. BR, SR, and TN conducted the study. BR and $\mathrm{TN}$, analyzed, interpreted the data, and wrote the first draft of the manuscript. All authors took part of the final version of the manuscript.

\section{Acknowledgements}

In memoriam of Dr. Anna Kernell, who died in 2010. We thank Lotta Larsson and Christina Häll for their excellent technical assistance. This work was supported by the Swedish Child Diabetes Foundation, the Swedish Diabetes Foundation, the "Mjölkdroppen" Foundation, the Swedish Heart and Lung Foundation, the Swedish Society for Medical Research, the Swedish Society of Medicine, the Loo and Hans Ostermans Foundation, and by funds of Karolinska Institutet. None of the funding sources had any involvement in the study design; collection, analysis, or interpretation of data; the writing of the report; or the decision to submit the paper.

\section{Author details}

'Karolinska Institutet, Department of Clinical Science and Education, Sachs' Childrens' Hospital, Södersjukhuset AB, Stockholm SE-118 83, Sweden. ${ }^{2}$ Karolinska Institutet, Department of Clinical Science and Education, Section of Clinical Physiology, Södersjukhuset AB, Stockholm, Sweden. ${ }^{3}$ Karolinska Institutet, Department of Clinical Science and Education, Division of Internal Medicine, Södersjukhuset AB, Stockholm, Sweden.

Received: 17 September 2012 Accepted: 22 November 2012 Published: 27 November 2012

\section{References}

1. The effect of intensive treatment of diabetes on the development and progression of long-term complications in insulin-dependent diabetes mellitus. The Diabetes Control and Complications Trial Research Group. N Engl J Med 1993, 329(14):977-986.

2. Krolewski AS, Kosinski EJ, Warram JH, Leland OS, Busick EJ, Asmal AC, Rand LI, Christlieb AR, Bradley RF, Kahn CR: Magnitude and determinants of coronary artery disease in juvenile-onset, insulin-dependent diabetes mellitus. Am J Cardiol 1987, 59(8):750-755

3. Berenson GS, Srinivasan SR, Bao W, Newman WP 3rd, Wattigney WA: Association between multiple cardiovascular risk factors and atherosclerosis in children and young adults. The Bogalusa Heart Study. N Engl J Med 1998, 338(23):1650-1656.

4. Giannini C, Mohn A, Chiarelli F, Kelnar CJ: Macrovascular angiopathy in children and adolescents with type 1 diabetes. Diabetes Metab Res Rev 2011, 27(5):436-460.

5. Järvisalo MJ, Jartti L, Nanto-Salonen K, Irjala K, Ronnemaa T, Hartiala JJ, Celermajer DS, Raitakari OT: Increased aortic intima-media thickness: a marker of preclinical atherosclerosis in high-risk children. Circulation 2001, 104(24):2943-2947.

6. Makinen VP, Forsblom C, Thorn LM, Waden J, Gordin D, Heikkila O, Hietala K Kyllonen L, Kyto J, Rosengard-Barlund M, et al: Metabolic phenotypes, vascular complications, and premature deaths in a population of 4,197 patients with type 1 diabetes. Diabetes 2008, 57(9):2480-2487.

7. Pambianco G, Costacou T, Orchard TJ: The prediction of major outcomes of type 1 diabetes: a 12-year prospective evaluation of three separate definitions of the metabolic syndrome and their components and estimated glucose disposal rate: the Pittsburgh Epidemiology of Diabetes Complications Study experience. Diabetes Care 2007, 30(5):1248-1254.

8. Kilpatrick ES, Rigby AS, Atkin SL: Insulin resistance, the metabolic syndrome, and complication risk in type 1 diabetes: "double diabetes" in the Diabetes Control and Complications Trial. Diabetes Care 2007, 30(3):707-712

9. Davis NL, Bursell JD, Evans WD, Warner JT, Gregory JW: Body composition in children with type 1 diabetes in the first year after diagnosis: relationship to glycaemic control and cardiovascular risk. Arch Dis Child 2012, 97(4):312-315.

10. Eddy D, Schlessinger $L$, Kahn R, Peskin B, Schiebinger R: Relationship of insulin resistance and related metabolic variables to coronary artery disease: a mathematical analysis. Diabetes Care 2009, 32(2):361-366.

11. Palombo C, Kozakova M, Morizzo C, Gnesi L, Barsotti MC, Spontoni $P$, Massart F, Salvi P, Balbarini A, Saggese G, et al: Circulating endothelial progenitor cells and large artery structure and function in young 
subjects with uncomplicated type 1 diabetes. Cardiovasc Diabetol 2011, 10:88.

12. Lamotte C, lliescu C, Libersa C, Gottrand F: Increased intima-media thickness of the carotid artery in childhood: a systematic review of observational studies. Eur J Pediatr 2011, 170(6):719-729.

13. Dengel DR, Jacobs DR, Steinberger J, Moran AM, Sinaiko AR: Gender differences in vascular function and insulin sensitivity in young adults. Clin Sci (Lond) 2011, 120(4):153-160

14. Atabek ME, Kurtoglu S, Pirgon O, Baykara M: Arterial wall thickening and stiffening in children and adolescents with type 1 diabetes. Diabetes Res Clin Pract 2006, 74(1):33-40.

15. Dalla Pozza R, Bechtold S, Bonfig W, Putzker S, Kozlik-Feldmann R, Netz H, Schwarz HP: Age of onset of type 1 diabetes in children and carotid intima medial thickness. J Clin Endocrinol Metab 2007, 92(6):2053-2057.

16. Tzou WS, Douglas PS, Srinivasan SR, Bond MG, Tang R, Chen W, Berenson GS, Stein JH: Increased subclinical atherosclerosis in young adults with metabolic syndrome: the Bogalusa Heart Study. J Am Coll Cardiol 2005, 46(3):457-463

17. Kotb NA, Gaber R, Salama M, Nagy HM, Elhendy A: Clinical and biochemical predictors of increased carotid intima-media thickness in overweight and obese adolescents with type 2 diabetes. Diab Vasc Dis: J Int Sci Diab Vasc Dis 2012, 9(1):35-41

18. Expert Panel on Detection, Evaluation, and Treatment of High Blood Cholesterol in Adults: Executive summary of the third report of the national cholesterol education program (NCEP) expert panel on detection, evaluation, and treatment of high blood cholesterol in adults (Adult Treatment Panel III). JAMA 2001, 285(19):2486-2497.

19. Organization WH: World Health Organization: Definition, Diagnosis and Classification of Diabetes Mellitus and Its Complications. Part I: Diagnosis and Classification of Diabetes Mellitus. Geneva, Switzerland: World Health Organization; 1999. Available at: http://whqlibdoc.who.int/hq/1999/ WHO_NCD_NCS_99.2.pdf. Accessed June 14, 2005. 2005.

20. Zimmet P, Alberti KG, Kaufman F, Tajima N, Silink M, Arslanian S, Wong G, Bennett $P$, Shaw J, Caprio S: The metabolic syndrome in children and adolescents - an IDF consensus report. Pediatr Diabetes 2007, 8(5):299-306.

21. Marshall WA, Tanner JM: Variations in pattern of pubertal changes in girls. Arch Dis Child 1969, 44(235):291-303.

22. Marshall WA, Tanner JM: Variations in the pattern of pubertal changes in boys. Arch Dis Child 1970, 45(239):13-23.

23. DeFronzo RA, Tobin JD, Andres R: Glucose clamp technique: a method for quantifying insulin secretion and resistance. Am J Physiol 1979, 237(3):E214-E223.

24. Wendelhag I, Gustavsson T, Suurkula M, Berglund G, Wikstrand J: Ultrasound measurement of wall thickness in the carotid artery: fundamental principles and description of a computerized analysing system. Clin Physiol 1991, 11(6):565-577

25. Wendelhag I, Liang Q, Gustavsson T, Wikstrand J: A new automated computerized analyzing system simplifies readings and reduces the variability in ultrasound measurement of intima-media thickness. Stroke 1997, 28(11):2195-2200.

26. Jensen-Urstad K, Rosfors S: A methodological study of arterial wall function using ultrasound technique. Clin Physiol 1997, 17(6):557-567.

27. Goldberger ZD, Valle JA, Dandekar VK, Chan PS, Ko DT, Nallamothu BK: Are changes in carotid intima-media thickness related to risk of nonfatal myocardial infarction? A critical review and meta-regression analysis. Am Heart J 2010, 160(4):701-714

28. Cardellini M, Marini MA, Frontoni S, Hribal ML, Andreozzi F, Perticone F, Federici M, Lauro D, Sesti G: Carotid artery intima-media thickness is associated with insulin-mediated glucose disposal in nondiabetic normotensive offspring of type 2 diabetic patients. Am J Physiol Endocrinol Metab 2007, 292(1):E347-E352.

29. Watarai T, Yamasaki Y, Ikeda M, Kubota M, Kodama M, Tsujino T, Kishimoto M, Kawamori R, Hori M: Insulin resistance contributes to carotid arterial wall thickness in patients with non-insulin-dependent-diabetes mellitus. Endocr J 1999, 46(5):629-638.

30. Wohlin M, Sundström J, Ärnlov J, Andrén B, Zethelius B, Lind L: Impaired insulin sensitivity is an independent predictor of common carotid intima-media thickness in a population sample of elderly men. Atherosclerosis 2003, 170(1):181-185

31. Fujiwara S, Emoto M, Komatsu M, Motoyama K, Morioka T, Koyama H, Shoji T, Inaba M, Nishizawa Y: Arterial wall thickness is associated with insulin resistance in type 2 diabetic patients. J Atheroscler Thromb 2003, 10(4):246-252.

32. Bokemark L, Wikstrand J, Attvall S, Hulthe J, Wedel H, Fagerberg B: Insulin resistance and intima-media thickness in the carotid and femoral arteries of clinically healthy 58-year-old men. The Atherosclerosis and Insulin Resistance Study (AIR). J Intern Med 2001, 249(1):59-67.

33. van Vliet M, Heymans MW, von Rosenstiel IA, Brandjes DP, Beijnen JH, Diamant M: Cardiometabolic risk variables in overweight and obese children: a worldwide comparison. Cardiovasc Diabetol 2011, 10:106.

34. Martinez-Vizcaino V, Ortega FB, Solera-Martinez M, Ruiz JR, Labayen I, Eensoo D, Harro J, Loit HM, Veidebaum T, Sjostrom M: Stability of the factorial structure of metabolic syndrome from childhood to adolescence: a 6-year follow-up study. Cardiovasc Diabetol 2011, 10:81.

35. Nadeau KJ, Regensteiner JG, Bauer TA, Brown MS, Dorosz JL, Hull A, Zeitler $P$, Draznin B, Reusch JE: Insulin resistance in adolescents with type 1 diabetes and its relationship to cardiovascular function. J Clin Endocrinol Metab 2010, 95(2):513-521.

36. Schauer IE, Snell-Bergeon JK, Bergman BC, Maahs DM, Kretowski A, Eckel RH, Rewers M: Insulin resistance, defective insulin-mediated fatty acid suppression, and coronary artery calcification in subjects with and without type 1 diabetes: The CACTI study. Diabetes 2011, 60(1):306-314.

37. Maahs DM, Nadeau K, Snell-Bergeon JK, Schauer I, Bergman B, West NA, Rewers M, Daniels SR, Ogden LG, Hamman RF, et al: Association of insulin sensitivity to lipids across the lifespan in people with Type 1 diabetes. Diabetic medicine: a journal of the British Diabetic Association 2011, 28(2):148-155.

38. Magnussen CG, Koskinen J, Chen W, Thomson R, Schmidt MD, Srinivasan SR, Kivimaki M, Mattsson N, Kahonen M, Laitinen T, et al: Pediatric metabolic syndrome predicts adulthood metabolic syndrome, subclinical atherosclerosis, and type 2 diabetes mellitus but is no better than body mass index alone: the Bogalusa Heart Study and the Cardiovascular Risk in Young Finns Study. Circulation 2010, 122(16):1604-1611.

39. Bonora E: The metabolic syndrome and cardiovascular disease. Ann Med 2006, 38(1):64-80.

40. Howard G, O'Leary DH, Zaccaro D, Haffner S, Rewers M, Hamman R, Selby JV, Saad MF, Savage P, Bergman R: Insulin sensitivity and atherosclerosis. The Insulin Resistance Atherosclerosis Study (IRAS) Investigators. Circulation 1996, 93(10):1809-1817.

41. Järvisalo MJ, Putto-Laurila A, Jartti $L$, Lehtimaki $T$, Solakivi $T$, Ronnemaa $T$, Raitakari OT: Carotid artery intima-media thickness in children with type 1 diabetes. Diabetes 2002, 51(2):493-498.

42. Polak JF, Backlund JY, Cleary PA, Harrington AP, O'Leary DH, Lachin JM, Nathan DM: Progression of carotid artery intima-media thickness during 12 years in the Diabetes Control and Complications Trial/Epidemiology of Diabetes Interventions and Complications (DCCT/EDIC) study. Diabetes 2011, 60(2):607-613.

43. Dalla Pozza R, Beyerlein A, Thilmany C, Weissenbacher C, Netz H, Schmidt H, Bechtold S: The effect of cardiovascular risk factors on the longitudinal evolution of the carotid intima medial thickness in children with type 1 diabetes mellitus. Cardiovasc Diabetol 2011, 10:53.

44. Effect of intensive diabetes treatment on carotid artery wall thickness in the epidemiology of diabetes interventions and complications. Epidemiology of Diabetes Interventions and Complications (EDIC) Research Group. Diabetes 1999, 48(2):383-390.

45. Muis MJ, Bots ML, Bilo HJ, Hoogma RP, Hoekstra JB, Grobbee DE, Stolk RP: High cumulative insulin exposure: a risk factor of atherosclerosis in type 1 diabetes? Atherosclerosis 2005, 181(1):185-192.

46. Sjöholm A, Nyström T: Endothelial inflammation in insulin resistance. Lancet 2005, 365(9459):610-612.

doi:10.1186/1475-2840-11-145

Cite this article as: Rathsman et al:: Early signs of atherosclerosis are associated with insulin resistance in non-obese adolescent and young adults with type 1 diabetes. Cardiovascular Diabetology 2012 11:145. 